\title{
Understanding Principal Investigators' Differences in Leadership Style and Perceptions of Teamwork to Leverage Leadership Development
}

\author{
Nicole L.P. Stedman, Ph.D. \\ Professor \\ University of Florida \\ Brittany L. Adams-Pope, Ph.D. \\ Assistant Professor \\ University of Louisville
}

\begin{abstract}
The purpose of this study was to begin exploring the nature of leadership behavior and style, as it relates to team functionality. The extent to which the problems we face grow and become more complex; solutions require multiple perspectives, requiring researchers to be prepared to lead large groups of collaborators from a variety of disciplines. This study sought to explore the self-perceptions of principal investigators related to their leadership style and team functionality. Using the Multifactor Leadership Questionnaire developed by Bass and Avolio (1995) and Lencioni's Team Assessment (2002), it was found that transformational leadership was self-perceived to be used the most in contrast to transactional leadership behaviors. With respect to team functionality, absence of trust and inattention to results showed the greatest concern to principal investigators, yet fear of conflict did not.
\end{abstract}

\section{Introduction}

Higher education is facing unique challenges today: increasing demand, limited resources, knowledge gaps, and the same amount of time to produce results, to name a few (Bruce \& Ricketts, 2008; Miller, Baird, Littlefield, Kofinas, Chapin, \& Redman, 2008). Budget cuts have forced researchers to adapt their work to be more efficient in the division of resources and knowledge (Minarovic, 2000). Minarovic also pointed out that sources of funding are also requiring more comprehensive research, forcing disciplines, such as those in agricultural sciences, to work together to receive funding. Stedman (2011) stated "Historically, many of the teams granted funds for research have been unidisciplinary in scope, providing only one perspective or view of the problem and thus, solution" (p. 2). Many researchers attest that many challenges associated with solving complex research problems are due to strict differences in approaches to research, which restrict holistic perspectives (Miller et. al, 2008; Minarovic, 2000). In response to these plentiful challenges, research is being conducted by interdisciplinary, multidisciplinary, and transdisciplinary groups.

Guion (2010) provided guidelines to follow when working in an interdisciplinary team, for example, recognize every team member's contributions, maximize members' expertise, and use a team approach, to name a few. However, Guion never described who would be leading the team or how, as well as who makes sure the team is following said guidelines. According to Stokols, et al. (2008), skills and styles of team leaders immensely influence the quality of social interactions in cross-disciplinary research. For this study, we investigated the role of principal investigators (PIs) in interdisciplinary research to begin exploring the nature of leadership behavior and style, as it relates to team functionality in an 
effort to improve effectiveness. Empirical data collection was used to determine what types of leader behaviors are effective in interdisciplinary research teams. The theoretical framework and a thorough literature review are found in the following paragraphs.

\section{Theoretical Framework and Literature Review}

Principal investigators of cross-disciplinary research play a pivotal role in the way multiple disciplines collaborate to answer complex research questions (Guion, 2010). One vantage point for researching the quality of interactions between interdisciplinary teams is to determine the teams' perception of the leadership and teamwork (Stedman, 2011). As teambuilding efforts in cross-disciplinary research become more prevalent, the need to assess the leadership behaviors of principal investigators becomes more important. The qualities and perceptions those PIs have regarding leadership and teamwork may give insight into how research teams function (Stedman, 2011).

\section{Transformational Leadership}

In the early works of Tichy and DeVanna, they applauded the work of transformational leaders (1990). The transformational leader was identified for their role in providing vision because the environment, had in fact, become less predictable. Like the problems researchers are facing and working to solve, the unpredictable nature of our world is continuing to increase. Transformational leadership was identified as a core leadership perspective to consider for this particular population of interest. Specifically, transformational leadership was operationalized using the perspectives of Antonakis, Avolio, and Sivasubramaniam (2003).

Antonakis, et al. (2003) operationalized transformational leadership behaviors to include four characteristics. Idealized Influence: leaders display conviction; emphasize trust; take stands on difficult issues; present their most important values; and emphasize the importance of purpose, commitment, and the ethical consequences of decision. Such leaders are admired as role models; they generate pride, loyalty, confidence, and alignment around a shared purpose. Inspirational Motivation: leaders articulate an appealing vision of the future; challenge followers with high standards; talk optimistically and with enthusiasm; and provide encouragement and meaning for what needs to be done. Intellectual Stimulation: Leaders question old assumptions, traditions, and beliefs; stimulate in others new perspectives and ways of doing things; and encourage the expression of ideas and reasons. Individualized Consideration: Leaders deal with others as individuals; consider their individual needs, abilities and aspirations; listen attentively; further their development; advise; and coach.

Transactional Leadership. Transactional leadership was operationalized with the following two characteristics: Contingent Reward: leaders engage in a constructive path-goal transaction of reward for performance. They clarify expectations, exchange promises and resources; arrange mutually satisfactory agreements; negotiate for resources; exchange assistance for effort; and provide commendations for successful follower performance. Management-by-Exception: active-leaders monitor followers' performance and take corrective action if deviations from standards occur; enforce rules to avoid mistakes. Passiveleaders fail to intervene until problems become serious and wait to take action until mistakes are brought to their attention (Antonakis, Avolio, \& Sivasubramaniam, 2003). 
Bruce and Ricketts (2008) addressed the stigma of inequitable resources by stating that education was the key to solving this problem in order for the environment of interdisciplinary teams to turn from hostility and separation to one of harmony and civility. However, what remains absent from Bruce and Ricketts discussion is the role that a principal investigator plays in making productivity and harmony characteristics of the environment among interdisciplinary groups. The role of the PI should be that of the administrator or manager, as previously referred to in Bruce and Ricketts' study (2008). However, principal investigator's leadership behaviors have failed to be an important topic discussed among researchers. The reason is unknown, but the benefits of knowing the role PIs play could alleviate or conquer some of the current challenges that interdisciplinary groups are facing (Bruce \& Ricketts, 2008). Cropper and Merkowitz (1998) recognized that interdisciplinary teamwork allows researchers to reduce replicated information and programming and point out that this interdisciplinary teamwork increases support for members of the team. In the following paragraphs, we outline leadership and teamwork from a theoretical perspective.

Scholars have been striving to understand how training can be implemented to improve the team aspects of cross-disciplinary research. According to Fiore (2008), many different types of training have been considered in order to improve the success of crossdisciplinary teams, such as team building, team dimensional training, cross training, and crew resource management. Fiore also stated, several theoretical approaches to leadership have been identified and applied in a range of industries, such as politics and the military. However, there lies a great opportunity for leadership to be assessed within cross-disciplinary research (Fiore, 2008). Ricketts and Bruce (2009) and Meier (1989) argued that leaders of agriculturally-based interdisciplinary teams are vital to the environment, collaboration, and communication of a team. Gray (2008) described leadership in cross-disciplinary research as a mental model, or mindset, that leaders impose and followers adhere. According to Huxham and Vangen (2000), leadership in multi-disciplinary teams provides "the mechanisms that lead a collaboration's policy and activity agenda in one direction rather than another" ( $\mathrm{p}$. 1165).

Key themes with regard to what traits and actions team leaders should possess and enact were prevalent in previous research. Stokols, et al., (2008) recommended that supportive and empowering leaders employ considerable support for team members in an academic setting. Young (2000) noted that leaders should be modest, benevolent, visionary, and strong. Young (2000) also identified a list of leadership tasks categorized as: cognitive, structural, and processual when conducting research on leadership roles in transdisciplinary research. Cognitive tasks refer to leadership involving the management of meaning. Leaders provide meaning by providing a map of goals and pathways for achievement, and simultaneously encouraging creativity from members and instilling motivation. Structural tasks of the leader involve managing the need for coordination and information exchange directly inside and outside the team. Furthermore, processual tasks involve the management. As outlined by Gray (2008) these tasks include: designing meetings, determining ground rules, helping teams move toward objectives, building trust, making certain communication is effective, attaining buy-in, and managing conflict.

Other themes have also been identified in regard to the environment of interdisciplinary research: tendencies toward conflict, collaborative readiness, and preparation and practice (Stokols et al., 2008). These three themes have overlapped with previous studies and research previously mentioned, such as Boone's (1990) recommendation that practice is the sure way to become more effective in participating in multidisciplinary 
teams. Stokols et al., (2008) have extensively constructed the contextual factors that apply for leadership application for effectiveness in interdisciplinary teams. As the need for interdisciplinary teams increase, Principal investigators must take a pensive view of themselves, investigating their behaviors and how these behaviors affect the success of interdisciplinary teams.

Teamwork. Lencioni's Five Dysfunctions of a Team (2002) were used to determine the teamwork aspect for this study; absence of trust, fear of conflict, lack of commitment, avoidance of accountability, and inattention to results. Absence of trust refers to team members who hesitate to ask for help, hesitate to offer help, hold grudges, dread meetings, and jump to negative conclusions about other team members (Lencioni, 2002). Fear of conflict refers to teams that have boring meetings, create environments were personal attacks thrive, ignore controversial topics, and waste time with posturing and interpersonal risks (Lencioni, 2002). Lack of commitment refers to teams that breed lack of confidence and fear of failure, revisit discussions again and again, and encourage second-guessing among team members (Lencioni, 2002). Teams that avoid accountability are teams who create resentment among members, miss deadlines, place the sole source of discipline on the leaders, and encourage mediocrity (Lencioni, 2002). Finally, teams that are not focused on results tend to be stagnant in growth, often defeated by competitors, easily distracted, and encourage team members to focus on personal growth not team growth (Lencioni, 2002).

According to Bruce and Ricketts (2008), teamwork is extremely important among cross-disciplinary groups in order to produce effective and efficient work. Collaboration has been the focus of much research (Bruce \& Ricketts, 2008; Grage, Place, \& Ricketts, 2004) relating to the effectiveness of multiple disciplines coming together to produce mutually beneficial results. Collaboration is defined as the act or work with others for mutual benefit (Bruce \& Ricketts, 2008). According to Whent (1994) in a study of agriculture teachers, when information sharing, team building, and assigned tasks were characteristic of groups, the amount of cooperation and resource sharing significantly increased. Fiore (2008) argues that interdisciplinary research is team research and this science of teams is a catalyst for change. Coordinating scientific teams is a process that does not naturally occur, but is learned. Fiore (2008) makes clear that researchers are often burdened by interdisciplinary research, because researchers feel they must have a great understanding of each discipline. However, Fiore makes the argument that when teams outside of scientific research come together, they do so by bringing unique skills to the problem needing solving and in this way solve the problems by connecting overlapping knowledge. Therefore, Fiore (2008) suggested that interdisciplinary research should be viewed through a teamwork lens, not as a product that emerges. The opportunities of team science in an interdisciplinary context help frame the concept of social intelligence, which is necessary in interdisciplinary teams (Fiore, 2008). According to Fiore (2008), this viewpoint could potentially make interdisciplinary research more amenable.

\section{Purpose}

The purpose of the current study was to explore the nature of leadership behavior and style, as it relates to team functionality and determine if their leadership style effected their perceptions of teamwork ability. The following objectives were established to provide guidance to the methodology of the study: 1) to identify PI's self-perceived leadership behaviors; 2) to describe PI's perceptions of teamwork; and 3) to report mean scores by the selected demographics of gender, age. Below, we outline the methodology of the study. 


\section{Methods}

The researchers used a quantitative descriptive study to assess the self-perceptions of Principal investigator's leadership behaviors and style, as well as teamwork. In order to accomplish this, the research team established an IRB protocol \#2011-U-0691. The study was partially funded through the National Institute of Food and Agriculture (NIFA) discretionary funds. NIFA provided the researchers with database access to projects funded within between 2005 and 2010 either through NIFA initiatives or through the United States Department of Agriculture (USDA). The initial database contained over 2000 research projects but was synthesized for duplicates resulting in 716 unique entries. Researchers used the Excel random number generator to select 408 participants from the pool of 716.

Two questionnaires were used as data collection tools. The Multifactor Leadership Questionnaire (MLQ) developed by Bass and Avolio (1995) was used to determine principal investigators leadership behaviors characterizing transformational and transactional leadership styles. Lencioni's Team Assessment (2002) was used to determine the potential for the five dysfunctions of a team to surface. Researchers adapted each instrument to be used via online distribution using Qualtrics software.

The MLQ was a 45-statement questionnaire measuring leadership based on leadership behaviors and styles Bass and Avolio (1995). Using a Likert-type scale, 1 (Not at all) to 5 (Frequently) respondents self-reported leadership style based on a number of behavior or factor statements. For the purposes of this study, the questionnaire was administered on the web, versus the traditional paper-based form. The reliability of leadership behaviors, or factors, ranged from .74 to .91 and leadership styles, or outcomes, ranged from .91 to .94 (Bass \& Avolio, 1995).

Transformational leadership was measured using 20 statements associated with the behaviors of idealized influence (behavior and attributed), intellectual stimulation, individualized consideration and inspirational motivation. Transactional leadership was measured using 12 statements based on the behaviors of contingent reward and managementby-exception (active and passive). Individual behavior statement scores were utilized to create an aggregate score for each leadership style. This is accomplished by averaging the total behavior score by the number of items. For transformational leadership style, this included the average of the summed scores for each transformational behavior ( 5 behaviors). Transactional leadership style was aggregated by the average of the summed scores for each transactional behavior ( 3 behaviors).

Lencioni's team assessment was a 15 item 3 point (Rarely, Sometimes and Usually), Likert-type assessment in which researchers revised to be a 5 point, Likert-type assessment (1-Strongly Disagree to 5-Strongly Agree). This revision was made, to provide greater specificity of the PIs perceptions of the behavior allowing the PI to more closely identify the extent to which they believed the teamwork behaviors were taking place. The five dysfunctions measured included: absence of trust, fear of conflict, lack of commitment, avoidance of accountability, and inattention to results. Each dysfunction was measured using three statements. For each dysfunction a higher score was considered to be less likely to result in negative teamwork functionality while low scores indicate a greater risk of negative teamwork functionality. 
For the first through third objectives, simple mean scores and standard deviations were calculated to describe the nature of leadership style and teamwork functionality by principal investigators. The fourth objective was accomplished using a Pearson Product Moment Correlation coefficient. In order to determine strength and direction of the relationship statistics the following parameters were used: $r=1.0$, perfect; $r=0.99-0.7$, very high; $r=0.69-0.50$, substantial; $r=0.49-0.30$, moderate; $r=0.29-0.10$, low; and $r=0.09-$ 0.01, negligible (Miller, 1998).

\section{Findings}

The demographics of the respondents varied and is important to illustrate in order to understand the nature of the findings. Of the 408 principal investigators randomly sampled, a total of 99 responded, with the number of useable responses being 82. To address the smaller rate of response for the online administration, non-response was controlled for using a comparison of early and late respondents (Lindner, Murphy \& Briers, 2001). Because of the lower response rate, the researchers opted to only use descriptive statistics as a means to analyze the data versus analysis using inferential. Because of this, the findings are limited to those respondents of the study.

Of the respondents, 40 were male and 28 were female, with the majority reporting they were Caucasian/White $(n=66)$ with only 2 reporting minority status. The largest age group was between 41 and $48(n=20)$ followed by 49-57 $(n=17)$ and 33-40 $(n=15)$. Age ranges were designed to coincide with ages associated with a particular faculty ranking. Of those who responded, the majority reported a bench or hard science discipline $(n=44)$ while the remainder indicated a social science discipline $(n=24)$. The greatest reported professorial rank was at the Assistant level $(n=27)$ followed by Full $(n=22)$ and Associate $(n=14)$.

Objective 1. Objective 1 was accomplished by reporting the following mean scores and standard deviations for the group of respondents. The total score for the transformational style of leadership was $M=3.89, S D=.61$ and the total for transactional style was $M=2.81$, $S D=.58$. Of the transformational behaviors the highest self-reported was individualized consideration $M=4.20, S D=.54$ followed by inspirational motivation $M=4.10, S D=.68$, intellectual stimulation $M=3.99, S D=.65$, idealized influence (behavior) $M=3.88, S D=.68$, and idealized influence (attribute) $M=3.71, S D=.81$. For the transactional behaviors the highest reported was contingent reward $M=3.76, S D=$. 74 followed by management-byexception (active) $M=2.59, S D=.89$, and management-by-exception (passive) $M=2.18, S D=$. 69. Table 1 represents these findings.

Table 1. Summary of Leadership Behavior and Style Scores

\begin{tabular}{llll}
\multicolumn{1}{c}{ Factor } & $n$ & $M$ & $S D$ \\
\hline IC & 67 & 4.20 & .54 \\
IM & 67 & 4.10 & .68 \\
IS & 67 & 3.99 & .65 \\
II B & 67 & 3.88 & .68 \\
CR & 67 & 3.76 & .74 \\
II A & 67 & 3.71 & .81 \\
MBE A & 67 & 2.59 & .89 \\
MBE P & 67 & 2.18 & .69 \\
Transformational & 67 & 3.89 & .61 \\
Transactional & 67 & 2.81 & .58 \\
\hline
\end{tabular}


Objective 2. The intent of objective 2 was to provide the respondents' perceptions of teamwork based on Lencioni's (2002) teamwork assessment. The behavior or dysfunction with the highest likelihood of resulting in negative team functionality was absence of trust $(M=10.06, S D=2.08)$ followed by inattention to results $(M=10.11, S D=1.55)$, avoidance of accountability $(M=10.31, S D=2.08)$, lack of commitment $(M=11.86, S D=1.82)$ and fear of conflict $(M=12.14, S D=1.47)$.

Objective 3. The goal of objective 3 was to provide a point of comparison for mean scores representing key demographic characteristics of the respondents. These demographics included gender, age, rank and discipline.

Leadership Style

In examining leadership style specifically, women scored themselves higher in transformational style $(M=4.15, S D=.40)$ than their male counterparts $(M=3.85, S D=.56)$ and also in transactional style $(M=3.00, S D=.55)$ with men self-scoring $(M=2.73, S D=.54)$. With respect to leadership style by age the youngest group (25-32) scored themselves highest in transformational behaviors $(M=4.23, S D=.78)$, followed by those 49-57 $(M=4.06, S D=.47)$, the lowest reported were those age 33-40 with $M=3.76, S D=$. 63. For transactional behaviors the highest scored were those in the age range of 66-73 with $M=3.08, S D=.00$ ) followed by 33-40 $(M=2.99, S D=.74)$ with the lowest reported by those in the age range of 25-32 $(M=2.56, S D=.46)$. Descriptive means are used to identify practical differences among the groups; this applies to all statistics referenced. These figures are represented in Table 2.

Table 2. Summary of Leadership Styles by Gender and Age

\begin{tabular}{lccccc}
\hline & & \multicolumn{2}{c}{ Transformational } & \multicolumn{2}{c}{ Transactional } \\
\cline { 3 - 6 } \multicolumn{1}{r}{ Factor } & $n$ & $M$ & $S D$ & $M$ & $S D$ \\
\hline Male & 39 & 3.85 & .56 & 2.73 & .54 \\
Female & 28 & 4.15 & .40 & 3.00 & .55 \\
$25-32$ & 03 & 4.23 & .78 & 2.56 & .46 \\
$33-40$ & 14 & 3.76 & .63 & 2.99 & .74 \\
$41-48$ & 20 & 4.03 & .44 & 2.90 & .51 \\
$49-57$ & 17 & 4.06 & .47 & 2.69 & .42 \\
$58-65$ & 11 & 3.94 & .51 & 2.82 & .63 \\
$66-73$ & 1 & 3.85 & .00 & 3.08 & .00 \\
\hline
\end{tabular}

Teamwork. Perceptions of teamwork functionality based upon gender showed that inattention to results was more likely to cause a negative team environment $(M=10.14$, $S D=1.78)$, followed by absence of trust $(M=10.36, S D=2.31)$ with the least likely being lack of commitment $(M=12.39, S D=1.34)$ for women. Men scored absence of trust the most likely $(M=9.85, S D=1.93)$ followed by avoidance of accountability $(M=10.13, S D=2.05)$ and least likely being fear of conflict $(M=12.00, S D=1.59)$. By age results varied with the most consistently reported dysfunction likely to cause a negative team environment being absence of trust with three age groups reporting that as their lowest score $(33-40 / M=9.60, S D=2.00$; $41-48 / M=9.95, S D=2.35$; and $58-65 / M=9.27, S D=2.15)$. The next most likely dysfunction was avoidance of accountability (33-40/M=10.27, $S D=2.15 ; 49-57 / M=10.12, S D=2.03$; and $58-65 / M=10.27, S D=2.80)$. Fear of conflict scored the highest (least likely) among the following age groups: 25-32 $(M=12.67, S D=1.54), 33-40(M=12.20, S D=1.26), 41-48(M=$ 
11.75, $S D=1.74)$ 49-57 $(M=12.29, S D=1.86)$, and 58-65 $(M=12.18, S D=1.08)$. These scores are represented in Table 4.

Table 4. Summary of Teamwork Perceptions by Gender and Age

\begin{tabular}{|c|c|c|c|c|c|c|c|c|c|c|c|}
\hline \multirow[b]{2}{*}{ Factor } & \multirow[b]{2}{*}{$n$} & \multicolumn{2}{|c|}{ Trust } & \multicolumn{2}{|c|}{ Conflict } & \multicolumn{2}{|c|}{ Commitment } & \multicolumn{2}{|c|}{ Avoidance } & \multicolumn{2}{|c|}{ Results } \\
\hline & & $M$ & $S D$ & $M$ & $S D$ & $M$ & $S D$ & $M$ & $S D$ & $M$ & $S D$ \\
\hline Male & 40 & 9.85 & 1.92 & 2.00 & 1.59 & 11.58 & 2.04 & 10.13 & 2.05 & 0.25 & 1.26 \\
\hline $\mathrm{Fem}$ & 28 & 10.36 & 2.31 & 12.25 & 1.43 & 12.39 & 1.34 & 10.54 & 2. & 14 & 1.78 \\
\hline & 0 & .00 & .00 & 7 & 1. & 12 & v & 9 & 2.5 & 3 & 1.54 \\
\hline 33 & 15 & 60 & 2.00 & 12.20 & 1.26 & 11.67 & 1.76 & 10.27 & 2.15 & 53 & 1.88 \\
\hline & 20 & 9.95 & 2.35 & 11.75 & 1.74 & 11.75 & 1.77 & 10.40 & 1.90 & 10.10 & 1.65 \\
\hline & 17 & 10.71 & 1.90 & 12.29 & 1.86 & 12.18 & 2.48 & 10.41 & 2.03 & 9.94 & 1.30 \\
\hline & & 9.27 & 2.15 & 2.18 & 1.08 & 11.91 & .83 & 10.23 & 2.80 & 10.45 & 1.04 \\
\hline $66-73$ & 01 & 10.00 & .00 & 12.00 & .00 & 13.00 & .00 & 10.00 & .00 & 10.00 & .00 \\
\hline
\end{tabular}

\section{Conclusions and Recommendations}

Each objective yielded interesting findings with respect to understanding the complexities of leadership style and teamwork functionality. Objective 1 indicated that overall principal investigators perceived themselves to be more transformational in leadership behavior, yet individually, scored contingent reward behaviors (transactional) higher than idealized influence (attribute/transformational). This is consistent with Bruce and Ricketts (2008) who purported that PI's should strive for productivity and harmony. Further, Guion (2010) indicated the nature of team member contribution as key, which is reflected in the top scoring leadership behavior individualized consideration.

Objective two highlighted the complex nature of teamwork and showed that absence of trust is a huge factor that PIs' perceive within their teams. Bruce and Ricketts (2008) indicated that there must be a change from hostility and separation in team environments to one of harmony and civility. This conclusion may be an indicator of the depth of this problem. Overall, however, the concept of lack of commitment and fear of conflict scored lowest. This idea is consistent with the notion that interdisciplinary researchers are coming together to solve complex problems and working together is a must (Cropper \& Merkowitz, 1998; Fiore, 2008).

Within objective three we begin to see the breakdown of perceptions by PIs' through a demographic lens. This indicates that women are more transformational than men, which is consistent with Northouse (2013). Women have opted for more democratic and participative leadership styles, which is represented with transformational leadership. Across age, there is a wider range of scores, but it appears that the younger PIs of the group also self-perceived more transformational behaviors. This is fairly consistent with literature indicating that organizational tenure (affiliated with age) tends to be more transactional, also represented in this study (Stedman \& Rudd, 2005).

Teamwork also ranged and had little established research to compare. However, women and men do rank order the potential for dysfunction to lead to issues of team functionality differently. Men move towards concepts of trust and accountability, while women tend towards inattention to results. Pretty consistent for the demographic of age was 
the nature of team functionality and that most agreed that the most likely factor was in fact, absence of trust. What did not appear to be an issue was fear of conflict for any group.

The last element of this study examined the nature of the relationship between leadership style and team functionality. It was shown that transformational leadership exhibited a moderate positive correlation with inattention to results. While it was not consistently scored the highest among all the groups analysed, inattention to results recurred enough that PI's clearly see it as a growing problem and perceived that the more transformational behaviors used the less likely it would be a contributing problem to team functionality.

The following recommendations have been outlined for this study with respect to research and practice. It is advised; however, that these only be utilized within the context of this study. To continue this line of inquiry additional research would be beneficial including, completing the study utilizing the $360^{\circ}$ assessments outlined for both the Multifactor Leadership Questionnaire and Lencioni's Teamwork Inventory. Further exploring the differences in perceptions based on gender and age would identify additional development needs. It is recognized that these groups are different, but inferential statistics could further identify the nature of the differences between these groups. It would be beneficial to qualitatively explore the nature of this phenomenon through small focus groups, allowing for more intimate discussion of the nature of team functionality and leadership. Lastly, research should explore other demographics like: proximity, appointment split, administrative experience, leadership development exposure, and teamwork/team leadership exposure. In the area of practice, specifically leadership development, there should be more hands-on leadership development to PIs. There is little documented on-going support for this group. Most current efforts are directed toward administrative functions. PIs should yield to more transformational behaviors, as they tend to show more gains in eliminating concerns of dysfunction among the team. The PIs of projects should be aware of the demographic makeup of their team and the impact this could have on how the team functions overall. Team members should also be coached on appreciating the breadth and depth of expertise brought by a diversity of backgrounds. Further, there should be an intense focus on issues related to absence of trust among teams.

The purpose of this study was to begin exploring the nature of teamwork and leadership behavior and style by principal investigators. In doing so, the conversation related to these topics and this area can yield greater gains in pursuing an understanding of how to make large interdisciplinary teams function better. In the coming years, the nature of the problems researchers are asked to solve are only going to grow in complexity requiring a greater range of input and support from a diversity of researchers. It is an important and valid concern that we recognize best how to create teams that are led by strong PI's who understand the nature of team functionality. 


\section{References}

Boone, E. J. (1990). Crossing Lines. Journal of Extension, 28 (3). Retrieved from http://www.joe.org/joe/1990fall/tp1.php

Bruce, J. A., \& Ricketts, K. G. (2008). Where's all the teamwork gone? A qualitative analysis of cooperation between members of two interdisciplinary teams. Journal of Leadership Education, 7(1), 65-75.

Cropper, R. J. \& Merkowitz, R. F. (1998). Cluster-a great way to work. Journal of Extension, 36 (1). Retrieved from http://www.joe.org.joe/1998february/iw2.php

Fiore, S. M. (2008). Interdisciplinarity as Teamwork: How the Science of Teams can inform Team science. Small Group Research, 39 (3), 251-277.

Grage, K. D., Place, N. T., \& Ricketts, J. C. (2004). Exploring cooperation between secondary agricultural educators and livestock extension agents: A case study. Journal of Extension, 42(6).

Gray, B. (2008). Enhancing transdisciplinary research through collaborative leadership. American Journal of Preventative Medicine, 35(2S), S124-S132.

Guion, L. (2010). A Checklist for Interdisciplinary Teams When Planning Issues-Based Programs. Journal of Extension, 48 (3). Retrieved from http://www.joe.org/joe/2010june/iw1.php

Huxham, C., \& Vangen, S. (2000). Leadership in the shaping and implementation of collaboration agendas: How things happen in a (not quite) joined up world. Academy Management Journal, 43, 1159-1175.

Lindner, J. R., Murphy, T. H., and Briers, G. E. (2001). Handling non-response in social science research. Journal of Agricultural Education 42(4), p. 43-53.

Meier. H. A. (1989). Extension Trends and Directions. Journal of Extension, 27 (3). Retrieved from http://www.joe.org/joe/1989fall/a3.php

Miller, L.E. (1998). Appropriate analysis. Journal of Agricultural Education, 39(2), 1-10.

Miller, R. T., Baird, T. D., Littlefield, C. M., Kofinas, G., Chaplin, F. S. III, \& Redman, C. L. (2008). Epistemological pluralism: Reorganizing interdisciplinary research. Ecology and Society, 13(2).

Minarovic, R. E. \& Mueller, J. P. (2000). North Carolina Cooperative Extension Service Professionals' Attitudes Toward Sustainable Agriculture. Journal of Extension, 38 (1).

Northouse, P. (2013). Leadership theory and practice (6 ${ }^{\text {th }}$ ed.). Los Angeles, CA: Sage Publications.

OECD/CERI. (2002). Understanding the brain. Towards a new learning science. Paris: OECD publications service. 
Ricketts, K. G. \& Bruce, J. A. (2009). "Co-opetition?" Can It Exist between Extension and Agricultural Education?-A Study on Interdisciplinary Cooperation. Journal of Extension, 47 (5). Retrieved from http://www.joe.org/joe/2009october/rb1.php

Stedman, N. L. P (2011). An Analysis of Principal Investigators' Perceptions of Leadership Behavior, Teamwork, and Motivation. Unpublished manuscript. Department of Agricultural Education and Communication, University of Florida, Gainesville, Florida.

Stedman, N. L. P., \& Rudd, R. D. (2005). Volunteer administration leadership proficiency and leadership styles: Perceptions of southern region 4-H county faculty. Journal of Leadership Education, 4(2), 42-58. Retrieved from http://www.fhsu.edu/jole/issues/Jole_4_2.pdf

Stokols, D., Misra, S., Moser, R. P., Hall, K. L., \& Taylor, B. K. (2008). The ecology of team science: understanding contextual influences on transdisciplinary collaboration. American Journal of Preventive Medicine, 35 (2). doi:10.1016/j.amepre.2008.05.003

Young, K. (2000). What makes transdisciplinary succeed or fail? In M. Somerville \& D. Rapport (Eds.), Transdisciplinarity: recreating integrated knowledge. Oxford, UK: EOLSS Publishers Ltd.

\section{Author Biographies}

Dr. Nicole L.P. Stedman is a Professor of Agricultural Leadership and Associate Chair in the Department of Agricultural Education and Communication at the University of Florida. Her current research focuses on the development of pedagogical strategies which enhance the development of critical thinking in learners. Her primary focus is in leadership development in both the undergraduate and graduate levels. Email: nstedman@ufl.edu

Dr. Brittany L. Adams-Pope is an Assistant Professor in the Equine Industry Program in the College of Business at the University of Louisville. She received her Ph.D. in Leadership Development at the University of Florida in 2013. Her research interests include authentic leadership, leadership development, and equine-assisted education and activites. Email: badamspope@gmail.com 